\title{
Correspondence
}

\section{More maneuvers to facilitate tracheal intubation with the GlideScope®}

To the Editor:

The GlideScope ${ }^{\circledR}$ (Diagnostic Ultrasound Corporation, Bothell, WA, USA), is a videolaryngoscope, which incorporates a fibreoptic and digital camera system into the blade. ${ }^{1}$ The blade displays a video output to a dedicated monitor. The flange of the blade has a $60^{\circ}$ angulation, which facilitates better exposure of the larynx than traditional Macintosh blades. ${ }^{2,3}$ Some authors have reported difficulty intubating the trachea despite the superior view offered by the GlideScope ${ }^{\circledR} .{ }^{1}$ In the largest series of Glidescope use (728 patients), 14 of the 26 failed intubations occurred in spite of achieving a Cormack-Lehane grade 1 view. ${ }^{4}$ In that study, failures resulted not from an inability to view the larynx, but in directing the endotracheal tube through the glottic opening. In our experience, the device has been successful in over 500 patients, especially those with large tongues, relatively small mouths, and in patients with limited neck mobility. We have used the device for conventional induction, in rapid sequence intubation, and for awake intubation. Because the GlideScope lifts the tongue rather than displacing it into the submental space, patients with Mallampati class III and IV airways are usually afforded CormackLehane grades 1 or 2 glottic views.

We have found the following maneuvers to be helpful when intubating the trachea with the GlideScope ${ }^{\circledR}$ :

1) Using a stylette, bend the endotracheal tube (ETT) into a "hockey stick" shape; this usually facilitates tracheal intubation if one obtains a Cormack-Lehane grade 1 view. If the larynx appears anteriorly, bending the ETT into a steeper curve is helpful. This can be achieved by emulating the bend of the GlideScope ${ }^{\circledR}$ flange and handle.

2) Introduce the ETT through the mouth in a horizontal plane, and once the tube has passed the flange of the GlideScope ${ }^{\circledR}$, rotate the ETT to the vertical position.

3 ) If the ETT advances posteriorly to the arytenoids, the following is helpful: With the ETT held between the fingertips, pull it superiorly, rotate the ETT over the left arytenoid, and gently twist the tube over the epiglottic aperture.

4) If the ETT abuts the glottic lip, rotate the ETT clockwise into the glottic aperture, while withdrawing the stylet. ${ }^{5}$

A midline approach and positioning to achieve an optimal laryngeal view is also important. The described maneuvers have helped the authors facilitate introduction of the ETT into the mouth, past the GlideScope ${ }^{\circledR}$, and decrease the risk of trauma to the posterior larynx and tracheal glottis. These approaches have also been very helpful in teaching proper use of the GlideScope $\AA$, and in managing failed tracheal intubations at our institution.

David C. Kramer MD

Irene P. Osborn MD

Mount Sinai Medical Center, New York, USA

E-mail: david.kramer@msnyuhealth.org

Accepted for publication March 20, 2006.

\section{References}

1 Rai MR, Dering A, Verghese C. The Glidescope system: a clinical assessment of performance. Anaesthesia 2005; 60: 60-4.

2 Hsiao WT, Lin $Y H, W u H S$, Chen CL. Does a new videolaryngoscope (GlideScope) provide better glottic exposure? Acta Anaesthesiol Taiwan 2005; 43: 147-51.

$3 \operatorname{Lim} T$ TJ, $\operatorname{Lim} \Upsilon$, Lin EH. Evaluation of ease of intubation with the GlideScope or Macintosh laryngoscope by anaesthetists in simulated easy and difficult laryngoscopy. Anaesthesia 2005; 60: 180-3.

4 Cooper RM, Pacey JA, Bishop MJ, McCluskey SA. Early clinical experience with a new videolaryngoscope (GlideScope) in 728 patients. Can J Anesth 2005; 52: 191-8.

5 Cuchillo JV, Rodriguez MA. Considerations aimed at facilitating the use of the new GlideScope videolaryngoscope (Letter). Can J Anesth 2005; 52: 661. 